\title{
Socio-seasonal changes in scent-marking habits in the carnivorous marsupial Dasyurus maculatus at communal latrines
}

\author{
Monica Ruibal ${ }^{\mathrm{A}, \mathrm{D}}$, Rod Peakall ${ }^{\mathrm{A}}$ and Andrew Claridge $\mathrm{B}, \mathrm{C}$ \\ AEvolution, Ecology and Genetics, Research School of Biology, The Australian National University, \\ Canberra, ACT 0200, Australia. \\ ${ }^{B}$ Department of Environment, Climate Change and Water, Parks and Wildlife Group, Planning and Performance \\ Unit, Southern Branch, Queanbeyan, NSW 2620, Australia. \\ ${ }^{\mathrm{C}}$ School of Physical, Environmental and Mathematical Sciences, University of New South Wales, \\ Australian Defence Force Academy, Northcott Drive, Canberra, ACT 2620, Australia. \\ DCorresponding author. Email: monica.ruibal@anu.edu.au
}

\begin{abstract}
Scat DNA analyses and monthly monitoring were used to elucidate patterns of latrine use in a free-ranging population of a rare Australian marsupial carnivore, the spotted-tailed quoll (Dasyurus maculatus) Kerr. In all, 132 latrines were identified at large complex outcrops and on bedrock in drainage lines, creeks and rivers at a single woodland site in south-eastern mainland Australia. Annual cyclic variation in scat deposition was found over the two years that latrines were monitored. Peaks in scat deposition on latrines coincided with seasonal social behaviours and differed between sites on outcrops and sites along drainage lines. A marked increase in scat deposition on latrines in drainage lines was recorded during the mating season and at outcrop latrines when females were nursing young. Genetic analyses of scats collected over one breeding season revealed that multiple individuals of both sexes defaecated at latrines. The communal use of latrines during the mating season along with the seasonal patterns of scat deposition demonstrates that latrines are important scent-marking sites that facilitate social communication among individuals of this solitary-living species. The collective evidence indicates that latrines play a major role in aiding reproduction and interindividual spacing.
\end{abstract}

\section{Introduction}

Scent-marking with faeces (scats), urine and glandular secretions is an important behaviour for aiding social communication in eutherian mammals (Stoddart 1976; Macdonald 1980, 1985; Gorman and Towbridge 1989) and marsupials (reviews by Eisenberg and Golani 1977; Russell 1985; Salamon 1996). The repetitive and on-going deposition of scats at landmarks is particularly common among carnivores (review by Macdonald 1985). These sites, called latrines or middens, can be used over many years and may confer information for: (1) demarcation of territories, (2) signalling ownership of resources, (3) facilitation of interindividual spacing (without territorial overtones), and (4) attracting mates by signalling sexual receptivity in females and individual presence or dominance in males (Stoddart 1976; Shorey 1977; Macdonald 1980, 1985; Croft 1982).

Latrine use has been reported in five free-ranging marsupial species: the spotted-tailed quoll (Dasyurus maculatus) (Alexander 1980; Belcher 1994; Kruuk and Jarman 1995), the northern quoll (D. hallucatus) (Oakwood 2002), the western quoll (D. geoffroii) (Serena and Soderquist 1989), the Tasmanian devil (Sarcophilus harrisii) (Pemberton 1990), and the rockhaunting possum (Petropseudes dahli) (Runcie 2004). However, despite some knowledge of the positioning of latrines, little is known about the participation or temporal pattern of latrine use by sex and age classes.

In the spotted-tailed quoll, accumulations of scats on prominent rocky features are reported by multiple authors (see Belcher 1994; Kruuk and Jarman 1995; Burnett 2001; Dawson 2005). However, detailed quantitative studies of sex, age and seasonal differences in scat deposition at various latrine types are required to assess the function of latrine use in this species. In this study, we combine for the first time radio-tracking, demographic and genetic analysis to investigate latrine use by the spotted-tailed quoll in detail. This complementary use of varied detection methods provides new insights into the use and social function of latrines by young and adult individuals of both sexes.

\section{Materials and methods \\ Trapping and radio-tracking of quolls}

This study was conducted in a 7000-ha area within the catchments of the Byadbo Wilderness Area, Kosciuszko National Park, south-eastern New South Wales, Australia. See Claridge et al. (2004, 2005, 2006) for detailed descriptions of the study location, topography, vegetation, climate and trapping program. Live trapping was conducted between April and July 2004-06 using 
wire mesh traps $(300 \times 300 \times 600 \mathrm{~mm}$, Mascot Wire Works, Enfield South, Australia), with pairs of traps set adjacent to latrine sites. On first capture, individuals were implanted with a Passive Integrated Transponder (PIT) (Trovan Microchips Australia, Melbourne) subcutaneously between the shoulder blades, and a tissue biopsy was taken and preserved in 70\% ethanol until DNA extraction. Sex was determined and age estimated based on weight (subadult $\sim 1$ year old: $q<1500 \mathrm{~g}, \hat{\sigma}<2000 \mathrm{~g}$; adults $2+$ years: $q>1500 \mathrm{~g}, \hat{\jmath}>2000 \mathrm{~g}$; as per Dawson 2005).

In May 2005, radio-collars were fitted (as described in Claridge and Mills 2007) to 16 individuals: six females, nine males, and one intersexual individual (individual with pouch and penis but lacking a scrotum, XXY karyotype: Ruibal 2008). All females were regularly tracked until early July 2005 on foot during daylight (hand-held yagi antenna, Australis 26K tracking receiver, Titley Electronics, Ballina, New South Wales, Australia). This allowed locations of den sites, type of den (small or large rock complex, burrow, log, or tree hollow), and position in the landscape (creek or river, midslope, ridge) to be determined. Targeted searching for all radio-collared individuals was also undertaken and helicopter-based telemetry provided additional locational fixes on all individuals as described in Claridge and Mills (2007).

\section{Temporal and socio-seasonal patterns} of scat scent marking

A monthly monitoring survey was conducted from November 2004 to October 2006 at 132 latrines (96 creek and 36 outcrop latrines). Prior to the survey all scats were removed during August 2004, allowing a two-month re-establishment period. Subsequently, the number of new scats was monitored. Temporal changes in scat scent-marking behaviour were examined in relation to socio-seasonal periods corresponding with distinct phases of the social and breeding biology of the spotted tailed quoll, and the growth cycle of its young: (1) mating season (April-June), (2) offspring dependent (July-October), (3) offspring weaning (November-December), and (4) offspring independent (January-March).

Generalised linear models assuming a Poisson distribution with a logarithmic link function and a Bernoulli distribution with a logit link function (observed $=1$, not detected $=0$ for each latrine per month) were used to analyse scat deposition variation over time and season. We also categorised the latrines into two types (creek versus outcrop) to assess differences between the latrine types. All statistical analyses were conducted using Genstat for Windows, 9th Edition (VSN International, Hemel Hempstead, UK) with statistical significance of each variable tested using deviance ratios (McCullagh and Nelder 1989).

\section{Sex and age patterns in scat scent-marking}

To elucidate sex and age patterns in scat scent-marking we matched unique microsatellite genotypes obtained from ear tissue DNA from the live-captured population against scat DNA samples collected from latrines (as detailed in Ruibal et al. 2009). Half of each new scat was collected at least every second day between April and July 2005 from a subset of latrines $(n=75)$. To simplify summaries we amalgamated proximate latrines (within $100 \mathrm{~m}$ ) into 26 sites.

\section{Results}

\section{Number of individuals identified}

Over the three years a total of 52 individuals were identified, 18 females, 33 males and an intersexual individual with 23-26 individuals known per year. Typically, there were more males than females and more adults than subadults (Table 1).

\section{Radio-tracking and den use}

In the northern section of the study area, radio-collared females showed some overlap in their home ranges with other females (Appendix 1 supplied as Accessory material on the Journal's website). Males also overlapped extensively in the areas they frequented with other males and with females (Appendix 2 supplied as Accessory material on the Journal's website). Females were located by radio-tracking at 30 different den sites. All known dens were subterranean burrows, with only $13 \%$ $(n=4)$ not associated with rocks. Most dens were located on the midslope or near ridges (79\%), rather than along drainage lines $(21 \%)$. Across all known dens, 11 were located at or near (within $60 \mathrm{~m}$ ) a latrine. Eight of these occurred at outcrops (six were known latrines) and three at latrines in creek lines.

\section{Temporal and socio-seasonal patterns in scat deposition} at latrines

The variation in scat deposition was broadly similar over the two years, exhibiting annual cyclic patterns (Figs 1, 2). Some temporal differences were found between the creek and outcrop latrines (Fig. 3). Temporal changes coincided with behavioural

Table 1. Summary of the trapping records per survey year and the numbers of individuals identified within each sex and age class

Also includes summary on the individuals identified via non-invasive scat and hair DNA sampling, in 2005 and 2006 respectively (Ruibal et al. 2010)

\begin{tabular}{|c|c|c|c|}
\hline & 2004 & 2005 & 2006 \\
\hline Survey dates & $\begin{array}{l}\text { 10-21 May, 15-25 June, } \\
\text { 26-30 July, 16-18 Aug. }\end{array}$ & 2-26 May, 4-21 July & $\begin{array}{c}\text { 14-18 April, 2-12 May, } \\
\text { 4-14 July }\end{array}$ \\
\hline No. of survey nights (and trapping effort) & $36(1370)$ & $28(1563)$ & $26(1408)$ \\
\hline No. of live-trapped individuals & $26(10+16$ 今 $)$ & $\begin{array}{l}22\left(6+: 15 \delta^{\wedge}\right)+1 \\
\text { intersexual }^{\mathrm{A}}\end{array}$ & $\begin{array}{l}21\left(6+14 \jmath^{1}\right)+1 \\
\text { intersexual }^{\mathrm{A}}\end{array}$ \\
\hline Additional individuals observed via non-invasive DNA & - & 2 ㅇ, $1 \hat{\jmath}$ & $2 \hat{0}$ \\
\hline Proportion of males & $62 \%$ & $67 \%$ & $73 \%$ \\
\hline Proportion of subadults ( $<1$ year old) & $16 \%$ & $35 \%$ & $32 \%$ \\
\hline
\end{tabular}

\footnotetext{
${ }^{\mathrm{A}}$ Individual with pouch and penis but lacking a scrotum, XXY karyotype (Ruibal 2008).
} 


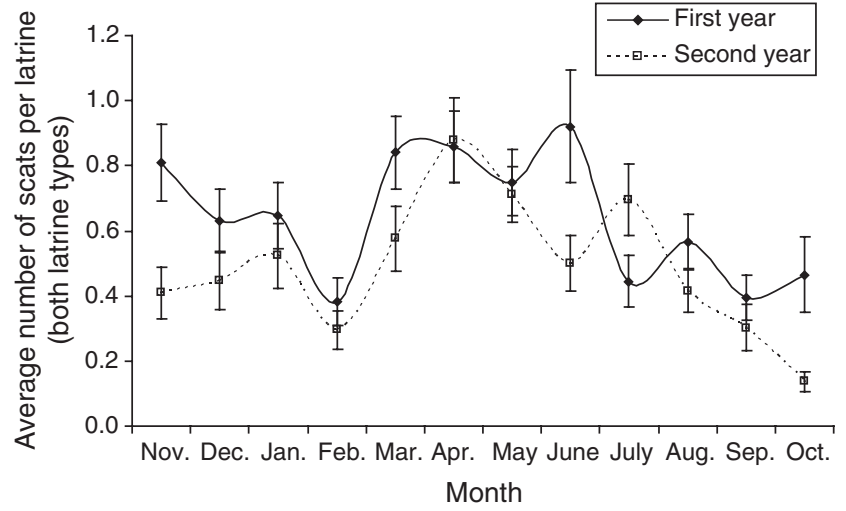

Fig. 1. Comparison of the average number ( \pm s.e.) of scats deposited at each of the 132 latrines per month in each monitored year.

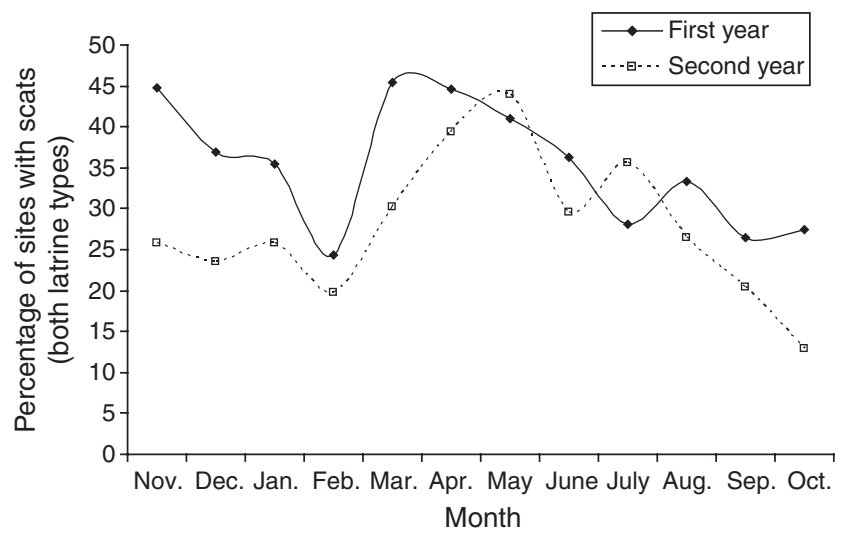

Fig. 2. Comparison of the proportion (\%) at each of the 132 latrine sites with at least one scat deposited during monthly periods in each monitored year.

changes associated with reproduction (Fig. 3). For example, deposition peaked at creek line latrines during the mating period then dropped sharply when females had pouch young. Low rates of deposition continued during the offspring-dependent period. During the offspring-independent period the rate of scat deposition declined at the outcrop latrines, but increased at the creek latrines.

Linear modelling revealed significant variation in the proportion of latrines with a scat present (Table 2) and the average number of scats deposited at the latrines (Table 3) over time, among the type of latrine, and among seasonal periods (type $\times$ season interaction). Thus the major influence of the overall variation was the type of latrine and socio-seasonal periods.

\section{Scat deposition by individuals during the mating and post-mating period}

In total, 262 scats were collected from 26 latrine sites (56 latrine platforms) over the four-month scat survey (April-July 2005). DNA was retrieved from 208 scats. Twenty-eight unique genotypes were identified; 18 matched known 2005 individuals, and two were matched to 2006 individuals. Four male adults of the 2005-trapped population were not sampled via scat

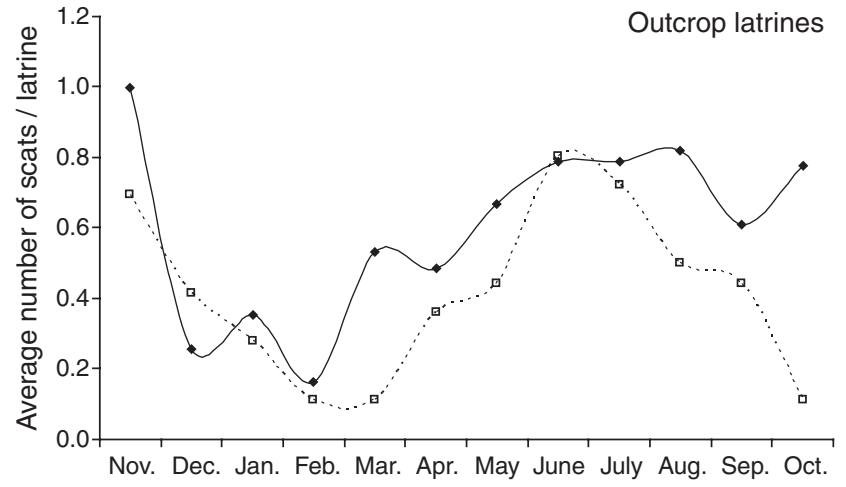

\begin{tabular}{|l|c|l|l|l|l|}
\hline $\begin{array}{c}\text { Offspring } \\
\text { weaning }\end{array}$ & $\begin{array}{c}\text { Offspring } \\
\text { independent }\end{array}$ & $\begin{array}{l}\text { Mating } \\
\text { season }\end{array}$ & Gestation & \multicolumn{2}{|c|}{$\begin{array}{c}\text { Offspring dependent } \\
\text { Pouch young }\end{array}$} \\
\hline
\end{tabular}

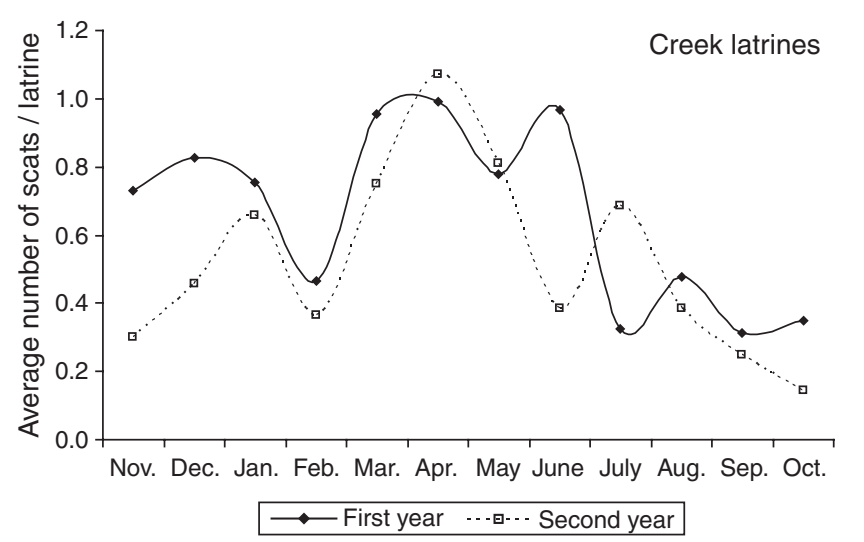

Fig. 3. Comparison of the average number of scats detected at outcrop $(n=36)$ and creek $(n=96)$ latrines in each of the monitored years. Socioseasonal periods corresponding with the breeding biology and the growth cycle of young are shown.

Table 2. Outcomes of generalised linear modelling of the proportion (\%) of latrines observed with at least one fresh scat at the two types of latrines (creek versus outcrop latrines) to test for differences in scat deposition

\begin{tabular}{|c|c|c|c|c|}
\hline Change & d.f. & Deviance & Mean deviance & $\sim F$ \\
\hline \multicolumn{5}{|c|}{ First year (November 2004-October 2005) } \\
\hline Type & 1 & 0.28 & 0.28 & 0.595 \\
\hline Season & 3 & 16.50 & 5.50 & $<\mathbf{0 . 0 0 1}$ \\
\hline Month & 8 & 16.97 & 2.12 & 0.03 \\
\hline Type $\times$ season & 3 & 23.43 & 7.81 & $<0.001$ \\
\hline Type $\times$ month & 8 & 4.19 & 0.52 & 0.84 \\
\hline Residual & 1441 & 1840.86 & 1.28 & \\
\hline Total & 1464 & 1902.23 & 1.30 & \\
\hline \multicolumn{5}{|c|}{ Second year (November 2005-October 2006) } \\
\hline Type & 1 & 6.33 & 6.33 & 0.012 \\
\hline Season & 3 & 25.17 & 8.39 & $<0.001$ \\
\hline Month & 8 & 31.00 & 3.88 & $<0.001$ \\
\hline Type $\times$ season & 3 & 12.56 & 4.19 & 0.006 \\
\hline Type $\times$ month & 8 & 13.88 & 1.74 & 0.085 \\
\hline Residual & 1560 & 1780.93 & 1.14 & \\
\hline Total & 1583 & 1869.87 & 1.18 & \\
\hline
\end{tabular}


Table 3. Outcomes of generalised linear modelling of the number of scats observed at the two types of latrines (creek versus outcrop latrines) to test for differences in scat deposition

\begin{tabular}{lcccc}
\hline Change & d.f. & Deviance & Mean deviance & $\sim F$ \\
\hline First year (November & $2004-$ October 2005) & & \\
Type & 1 & 0.99 & 0.99 & 0.42 \\
Season & 3 & 52.16 & 17.39 & $<\mathbf{0 . 0 0 1}$ \\
Month & 8 & 28.69 & 3.59 & $\mathbf{0 . 0 1 6}$ \\
Type $\times$ season & 3 & 53.11 & 17.70 & $<\mathbf{0 . 0 0 1}$ \\
Type $\times$ month & 8 & 18.30 & 2.29 & 0.149 \\
Residual & 1441 & 2184.87 & 1.52 & \\
Total & 1464 & 2338.13 & 1.60 & \\
Second year (November $2005-$ October 2006$)$ & & \\
Type & 1 & 6.95 & 6.95 & $\mathbf{0 . 0 2 2}$ \\
Season & 3 & 45.27 & 15.09 & $<\mathbf{0 . 0 0 1}$ \\
Month & 8 & 85.66 & 10.71 & $<\mathbf{0 . 0 0 1}$ \\
Type $\times$ season & 3 & 38.58 & 12.86 & $<\mathbf{0 . 0 0 1}$ \\
Type $\times$ month & 8 & 37.69 & 4.71 & $<\mathbf{0 . 0 0 1}$ \\
Residual & 1560 & 2069.13 & 1.33 & \\
Total & 1583 & 2283.28 & 1.44 & \\
\hline
\end{tabular}

DNA. The 20 genotypes matched to known individuals included adults $(n=12)$ and subadults $(n=8)$ of each sex (adults: $\hat{o}=7$, $q=5$; subadults: $\hat{\delta}=5, \quad+=2$; and 1 subadult intersexual individual).

DNA was successfully amplified from 149 of $183(81.4 \%)$ scats from creek latrines and 59 of $79(74.7 \%)$ scats from outcrops over 23 latrine sites (of 26). Most (74\%) latrine sites had scats from both sexes (Appendix 1). The total number of individuals using a given latrine site varied from one to seven (average 3.5) with up to six males but at most two females per site (Table 4). Males of each age cohort (subadult $n=5$, adult $n=7$ ) used latrines in most months (data not shown). Females of each age cohort (subadult $n=2$, adult $n=5$ ) used latrines each month from April until 2 July (data not shown). After this date, and until 22 July when the sampling period ceased, none of the scats collected were attributed to females. Thus, the marking strategy of females altered in July, coinciding with the birth of young (three of the four females trapped in July/August had pouch young present: M. Ruibal, unpubl. data).
Over the period when both sexes were marking, scats from females were encountered, on average, at a similar rate to those from males (mean \pm s.e.: $q 9.1 \pm 3.1$, range $=2-27, n=8$; o $8.9 \pm 2.7$, range $=1-37, n=12$ ). Subadults were detected more often than adults (subadult $12.1 \pm 4.6$, range $=1-37, n=8$; adults $7.3 \pm 1.6$, range $=2-18, n=12$ ). Among males, subadults were observed, on average, more often than adults ( $\hat{o}$ subadult $11.4 \pm 5.6$, range $=1-37, n=5$; $\widehat{o}$ adults $8.4 \pm 2.4$, range $=2-18$, $n=7)$. Scats belonging to both sexes and age classes were found at the two latrine types. On a monthly basis, the number of females detected at outcrop latrines was two or three and males four (Table 5). In contrast, at creek latrines most females were detected each month (6 or 7 females), except for July. Also, more males were detected in each month at creek latrines than at outcrop latrines (Table 5).

\section{Discussion}

Non-invasive DNA sampling of scats from latrines, in combination with a DNA and demographic database on trapped individuals has provided, for the first time, unique insights into the use of latrines by spotted-tailed quolls. All animals in the population, regardless of sex or age, used latrines, with annual cycles in the frequency of scat deposition and variation that coincided with seasonal social behaviours. It is thus evident that scats are actively used as a scent signal (under Kleiman's (1966) criteria) and latrine-forming behaviours have multiple functions. Here we use scat-deposition data to consider these possible functions

\section{Functional significance for reproduction}

A reproductive function is widely assumed when scent-marking behaviours increase or are restricted to the breeding period (see Macdonald 1980; Gorman and Towbridge 1989). We observed a marked increase in scat deposition and the proportion of latrines used during the mating period consistent with qualitative evidence in other studies of spotted-tailed quolls (Alexander 1980; Belcher 1994; Dawson 2005), and of the northern quoll (D. hallucatus) (Oakwood 2002). Latrine use for reproduction by spotted-tailed quolls may function both to advertise female sexual receptivity and male presence or dominance.

Table 4. Numbers of the average and range of individuals identified from scat DNA collected between April and the end of July 2005 from single latrines (per single rock feature) and latrine sites (where several latrines occurred within an outcrop complex or $<100 \mathrm{~m}$ of each other along a creek line) Summaries are provided for single rock features and latrines grouped by proximity to show that an equivalent average number of individuals and range of individuals were observed with amalgamation of latrines. Also, similar numbers of individuals were observed when individuals identified solely from scat DNA were excluded. Latrines from which fewer than two scats were collected are not included

\begin{tabular}{|c|c|c|c|c|c|}
\hline & & \multicolumn{2}{|c|}{ Individuals per latrine } & \multicolumn{2}{|c|}{ Individuals per site ${ }^{\mathrm{A}}$} \\
\hline & & Average & Range & Average & Range \\
\hline All individuals identified by means of scat DNA & Total $(n=28)$ & $2.6^{\mathrm{B}}$ & $1-6$ & 3.5 & $1-7$ \\
\hline Excluding transient individuals identified via scat & Females $(n=8)^{\mathrm{D}}$ & $0.9^{\mathrm{C}}$ & $0-2$ & 1.1 & $0-2$ \\
\hline DNA only once or solely in April & Males $(n=12)^{\mathrm{E}}$ & $1.5^{\mathrm{C}}$ & $0-5$ & 1.8 & $0-6$ \\
\hline & Total $(n=21)^{\mathrm{F}}$ & $2.5^{\mathrm{C}}$ & $1-6$ & 3.0 & $1-7$ \\
\hline
\end{tabular}

${ }^{\mathrm{A}} n=23$ sites. ${ }^{\mathrm{B}} n=40$ single rocks. ${ }^{\mathrm{C}} n=37$ single rocks. ${ }^{\mathrm{D}}$ Includes one unknown individual that was determined to be female given the non-amplification of $S R Y$ gene and amplification of a control marker (see Ruibal 2008). ${ }^{\mathrm{E}}$ Four adult male individuals trapped in 2005 were not identified via the scat DNA collection

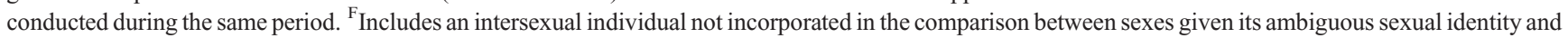
therefore behaviour. 
Table 5. Summary of the number of scats for each sex collected at outcrop and creek latrines that yielded DNA

The number of individuals identified is shown in parentheses. The number of scats for which no DNA was retrieved at each of the latrine types is also shown

\begin{tabular}{llcccc}
\hline Latrine type & Sex & April $^{\mathrm{A}}$ & May $^{\mathrm{A}}$ & June $^{\mathrm{A}}$ & July $^{\mathrm{A}}$ \\
\hline Outcrop & Female $(n=8)$ & $8(2)$ & $3(3)$ & $15(2)$ & 0 \\
& Male $(n=12)$ & 0 & $4(3)$ & $19(4)$ & $5(4)$ \\
& No DNA & 2 & 6 & 10 & 3 \\
\multirow{4}{*}{ Creek } & Female $(n=8)$ & $18(7)$ & $12(7)$ & $15(6)$ & $2(2)$ \\
& Male $(n=12)$ & $21(7)$ & $20(7)$ & $39(8)$ & $8(4)$ \\
& No DNA & 12 & 11 & 9 & 1 \\
\hline
\end{tabular}

${ }^{\mathrm{A}}$ Summaries exclude an intersexual individual and scat samples belonging to 7 individuals unknown from the trapped population, but include one unknown female individual (Ruibal 2008).

Scent marking by females may allow them to advertise their pending sexual state to attract potential mates (Clapperton 1989). The duration of female attractiveness to males varies between species but is known to begin before they enter oestrus (Ewer 1968; Russell 1984). The benefit of a prolonged preoestrous period of attractiveness, particularly in solitary species where female-male encounters are not regular, is that it ensures that males are present when females are ovulating, and thus secures mating opportunities (Ewer 1968).

The finding that all female spotted-tailed quolls used latrines in April, before litters were conceived, then ceased to mark when offspring were born suggests that this may allow females to advertise their pending sexual state to attract potential mates. If so, this would provide an efficient means for males to monitor female receptiveness, while minimising unwarranted copulations or aggression. A preoestrous period of attractiveness is also likely to enhance opportunities for polyandry. Mixed-paternity litters have indeed been revealed by paternity analysis of spotted-tailed quolls (Glen et al. 2009).

Scent marking by males can be used to simultaneously signal their presence to females and competing males, where dominant or larger males mark at a greater rate to signal their status (Gorman and Towbridge 1989). This could allow subordinate males to avoid confrontation with a dominant individual, while allowing females to assess mate quality (Rich and Hurst 1998; Hurst and Rich 1999; Begg et al. 2003). A dominance hierarchy based on size and age is thought to operate among male spotted-tailed quolls (Belcher 2000; Andrew 2005; Glen et al. 2009), given the roving strategy adopted by males during the mating season, evidence for polyandry and paternity analysis revealing that larger males sire more young (Croft 2003; Croft and Eisenberg 2006; Glen et al. 2009). However, the finding in the present study of no difference in the scat-marking frequency between adult and subadult males, and no evidence that subadult males were deterred from marking at latrines, does not concur with the dominance hierarchy hypothesis.

\section{Functional significance for mediating spatial organisation}

Since scat deposition in the spotted-tailed quoll occurs throughout the year, latrines must have other functions beyond a reproductive role. Our finding that scat deposition by both sexes was greater at creek than outcrop latrines during the mating period suggests that individuals made strategic decisions about scat placement to maximise discovery. The low relief and linear configuration of creeks and rivers in the study area may assist the efficiency of the roving strategy of males. Accordingly, females too would maximise the number of potential sires by scent-marking more often in areas where several males may be encountered. Latrines occurring on linear features (paths and river crossings) were also more heavily used by the western quoll, leading Serena and Soderquist (1989) to postulate that these were places where animal movements were likely to be concentrated.

In contrast to creek latrines, peak scat deposition at outcrop latrines occurred during the offspring-dependent period, often in proximity to known den sites. Therefore, scat deposition at outcrops during this period may function to advertise female occupancy of dens. The protection and exclusive use of limited resources (such as dens and food) is the motive invoked for female territoriality in all three quoll species (Serena and Soderquist 1989; Oakwood 2002; Belcher and Darrant 2004; Andrew 2005). However, given our finding that more than one female may scent mark at a latrine and that females with adjacent or overlapping home ranges are often closely related (Ruibal 2008), scentmarking may instead operate as a form of 'social book keeping' that enables females to keep track of related individuals and so maintain social cohesion. Females may also scent mark to aid their offspring's familiarisation with the natal area once their young make excursions outside the den and young may also begin to mark for the same purpose.

This study has confirmed for the first time that spotted-tailed quoll latrines are communal areas at which subadults and adults of each sex participate in scent-marking behaviours. Furthermore, we have shown that patterns of deposition vary both seasonally and in relation to the spatial location of latrines. These patterns indicate that latrines provide focal areas to exchange information for reproductive purposes, by attracting or seeking mates, and more generally for maintaining interindividual spacing. Finally, this study demonstrates the power of combining genetic analyses with observational and demographic data to gain greater insights into the significance of latrine-forming behaviours in an otherwise cryptic species.

\section{Acknowledgements}

We thank the numerous volunteers who assisted with the fieldwork over the three years of this study, particularly Warren Gardner for assisting with the monthly monitoring of latrines; James Dawson, Chris Howard and Alex Martin for improving earlier drafts of the manuscript; Chad Staples for advice provided on spotted-tail quoll behaviours; and Christine Donnelly, Emlyn Williams and Jeff Wood for statistical advice. Funding for this project was provided to M. Ruibal from The Australian National University, the Sophie Danforth Conservation Biology Fund, the Australian Academy of Science, the M.A Ingram Trust, the Estate of the Late Winifred Violet Scott, the Wildlife Preservation Society of Australia, and the NSW National Parks and Wildlife Service. The primary author was supported by an APA Ph.D. scholarship. All the fieldwork and collections were conducted under ethics approval from the Australian National University Animal Experimentation Ethics Committee (F.BTZ.75.04 \& F.BTZ78.04) and the NSW National Parks and Wildlife Service (NPWS) Animal Ethics Committee (No. 020214/05), as well as under the auspices of NSW NPWS Section 120 Scientific Investigation Licences (S11472 \& A3162). 


\section{References}

Alexander, D. (1980). Diet of the tiger quoll (Dasyurus maculatus Kerr) in an area of New England National Park, northeastern New South Wales. B.Nat.Res. Thesis, University of New England, Armidale.

Andrew, D. L. (2005). Ecology of the tiger quoll Dasyurus maculatus maculatus in coastal New South Wales. M.Sc. Thesis, University of Wollongong.

Begg, C., Begg, K., Du Toit, J., and Mills, M. (2003). Scent-marking behaviour of the honey badger, Mellivora capensis (Mustelidae), in the southern Kalahari. Animal Behaviour 66, 917-929. doi:10.1006/ anbe. 2003.2223

Belcher, C. A. (1994). Studies on the diet of the tiger quoll. M.Sc. Thesis, La Trobe University, Melbourne.

Belcher, C. A. (2000). Ecology of the tiger quoll Dasyurus maculatus in southeast Australia. Ph.D. Thesis, Deakin University, Melbourne.

Belcher, C. A., and Darrant, J. P. (2004). Home range and spatial organisation of the marsupial carnivore, Dasyurus maculatus maculatus (Marsupialia: Dasyuridae) in south-eastern Australia. Journal of Zoology 262, 271-280. doi:10.1017/S0952836903004631

Burnett, S. (2001). Ecology and conservation status of the northern spot-tailed quoll, Dasyurus maculatus, with reference to the future of Australia's marsupial carnivores. Ph.D. Thesis, James Cook University, Townsville.

Clapperton, B. K. (1989). Scent-marking behaviour of the ferret, Mustela vison. Animal Behaviour 38, 436-446. doi:10.1016/S0003-3472 (89)80037-5

Claridge, A. W., Mifsud, G., Dawson, J., and Saxon, M. J. (2004). Use of infrared digital cameras to investigate the behaviour of cryptic species. Wildlife Research 31, 645-650. doi:10.1071/WR03072

Claridge, A. W., and Mills, D. J. (2007). Aerial baiting for wild dogs has no observable impact on spotted-tailed quolls (Dasyurus maculatus) in a rainshadow woodland. Wildlife Research 34, 116-124. doi:10.1071/ WR06151

Claridge, A. W., Paull, D., Dawson, J., Mifsud, G., Murray, A. J., Poore, R., and Saxon, M. J. (2005). Home range attributes of the spotted-tailed quoll (Dasyurus maculatus), a marsupial carnivore, in a rainshadow woodland. Wildlife Research 32, 7-14. doi:10.1071/WR04031

Claridge, A. W., Murray, A., Dawson, J., Poore, R., Mifsud, G., and Saxon, M. (2006). The propensity of spotted-tailed quolls (Dasyurus maculatus) to encounter and consume non-toxic meat baits. Wildlife Research 33, 85-91. doi:10.1071/WR05039

Croft, D. B. (1982). Communication in the Dasyuridae (Marsupialia): a review. In 'Carnivorous Marsupials'. (Ed. M. Archer.) pp. 291-310. (Royal Zoological Society of New South Wales.)

Croft, D. B. (2003). Behaviour of carnivorous marsupials. In 'Predators with Pouches'. (Eds M. Jones, C. Dickman and M. Archer.) pp. 332-346. (CSIRO Publishing: Melbourne.)

Croft, D. B., and Eisenberg, J. F. (2006). Behaviour. In 'Marsupials'. (Eds P. Armati, C. Dickman and I. Hume.) pp. 229-299. (Cambridge University Press: Cambridge.)

Dawson, J. (2005). Impact of wildfire on the spotted-tailed quoll Dasyurus maculatus in Kosciuszko National Park. M.Sc Thesis, University of New South Wales, Sydney.

Eisenberg, J. F., and Golani, I. (1977). Communication in Metatheria. In 'How Animals Communicate'. (Ed. T. A. Seebok.) pp. 575-599. (Indiana University Press: Bloomington, IN.)

Ewer, R. F. (1968). 'Ethology of Mammals.' (J.W. Arrowsmith Ltd: Bristol.)

Glen, A. S., Cardoso, M. J., Dickman, C. R., and Firestone, K. B. (2009). Who's your daddy? Paternity testing reveals promiscuity and multiple paternity in the carnivorous marsupial Dasyurus maculatus. Biological Journal of the Linnean Society. Linnean Society of London 96, 1-7. doi:10.1111/j.1095-8312.2008.01094.x

Gorman, M. L., and Towbridge, B. J. (1989). The role of odor in the social lives of carnivores. In 'Carnivore Behaviour, Ecology, and Evolution'. (Ed. J. L. Gittleman.) pp. 57-86. (Cornell University Press: New York.)
Hurst, J. L., and Rich, T. J. (1999). Scent marks as competitive signals of mate quality. In 'Advances in Chemical Signals in Vertebrates'. (Eds R. E. Johnston, D. Muller-Schwarze and P. W. Sorensen.) pp. 209-226. (Plenum Publishers: New York.)

Kleiman, D. (1966). Scent marking in the Canidae. Symposium of the Zoological Society of London 18, 167-177.

Kruuk, H., and Jarman, P. J. (1995). Latrine use by the spotted-tailed quoll (Dasyurus maculatus: Dasyuridae, Marsupialia) in its natural habitat. Journal of Zoology 236, 345-349. doi:10.1111/j.1469-7998.1995. tb04501.x

Macdonald, D. W. (1980). Patterns of scent marking with urine and faeces amongst carnivore communities. Symposium of the Zoological Society of London 45, 107-139.

Macdonald, D. W. (1985). The carnivores: order Carnivora. In 'Social Odours in Mammals: Vol. 2'. (Eds J. A. Brown and D. W. Macdonald.) pp. 619-722. (Oxford University Press: Oxford.)

McCullagh, P., and Nelder, J. A. (1989). 'Generalized Linear Models.' 2nd edn. (Chapman and Hall: London.)

Oakwood, M. (2002). Spatial and social organisation of a carnivorous marsupial Dasyurus hallucatus (Marsupialia: Dasyuridae). Journal of Zoology 257, 237-248. doi:10.1017/S0952836902000833

Pemberton, D. (1990). Social organisation and behaviour of the tasmanian devil, Sarcophilus harrisii. Ph.D. Thesis, University of Tasmania, Hobart.

Rich, T. J., and Hurst, J. L. (1998). Scent marks as reliable signals of the competitive ability of mates. Animal Behaviour 56, 727-735. doi:10.1006/anbe.1998.0803

Ruibal, M. P. (2008). A field implementation and evaluation of non-invasive DNA methods for the spotted-tailed quoll (Dasyurus maculatus). $\mathrm{Ph} . \mathrm{D}$. thesis, The Australian National University, Canberra.

Ruibal, M. P., Peakall, R., Claridge, A., and Firestone, K. (2009). Field-based evaluation of scat DNA methods to estimate population abundance of the spotted-tailed quoll (Dasyurus maculatus), a rare Australian marsupial. Wildlife Research 36, 721-736. doi:10.1071/WR09086

Ruibal, M., Peakall, R., Claridge, A., Murray, A., and Firestone, K. (2010). Advancement to hair-sampling surveys of a medium-sized mammal: DNA-based individual identification and population estimation of a rare Australian marsupial, the spotted-tailed quoll (Dasyurus maculatus). Wildlife Research 37, 1-12.

Runcie, M. J. (2004). Scent-marking and vocal communication in the rockhaunting possum Petropseudes dahli. In 'The Biology of Australian Possums and Gliders'. (Eds R. L. Goldingay and S. M. Jackson.) pp. 401-412. (Surrey Beatty: Sydney.)

Russell, E. M. (1984). Social behaviour and social organisation of marsupials. Mammal Review 14, 101-154. doi:10.1111/j.1365-2907.1984.tb00343.x

Russell, E. M. (1985). The Metatherians: Order Marsupialia. In 'Social Odours in Mammals. Vol. 1'. (Eds R. E. Brown and D. W. Macdonald.) pp. 45-104. (Clarendon Press: Oxford.)

Salamon, M. (1996). Olfactory communication in Australian marsupials. In 'Comparison of Marsupial and Placental Behaviour'. (Eds D. B. Croft and U. Gansloßer.) pp. 46-79. (Filander Verlag: Furth.)

Serena, M., and Soderquist, T. R. (1989). Spatial organisation of a riparian population of the carnivorous marsupial Dasyurus geoffroii. Journal of Zoology 219, 373-383. doi:10.1111/j.1469-7998.1989.tb02586.x

Shorey, H. H. (1977). Pheromones. In 'How Animals Communicate'. (Ed. T. A. Seebok.) pp. 137-163. (Indiana University Press: Bloomington, IN.)

Stoddart, D. M. (1976). 'Mammalian Odours and Pheromones.' (Edward Arnold Ltd: London.)

Handling Editor: Chris Johnson

Manuscript received 4 June 2010, accepted 25 November 2010 